\title{
Exploring Relationship between Online Connectedness and Employee Perception of Supervisor Openness
}

\author{
Pius A. Onobhayedo \\ School of Media and Communication, \\ Pan-Atlantic University, Lagos, Nigeria
}

\begin{abstract}
As online connectedness continues to be a global phenomenon, this paper presents an examination of relationship between online connectedness of superior and subordinate, and the perceived openness of supervisors by employees. Using questionnaire as instrument, survey was carried out among employees in two countries (Nigeria and Spain) with disparate levels of infrastructure maturity as a way of facilitating generalizability of findings. Results show that the two connectedness scenarios studied were positively related to the perceived openness of managers by employees. It could be inferred from these findings that openness towards employees exhibited by supervisors online could enhance the level of positive communication climate in organizations as the latter has been suggested to be influenced by the perceived openness of the immediate supervisor.
\end{abstract}

Keywords: online connectedness, manager communication openness, organizational communication, social networks, presence awareness

\section{INTRODUCTION}

Connectedness has long been put forward as a key concept in the analysis of communication and the development of communication technology (Rettie, 2003). This suggestion seems appropriate given the advancements in information technology that increasingly facilitate person-to-person connection through the electronic media on the World Wide Web. The high level of adoption of such Web-based media has led to a world in which real-life connections are increasingly replicated on electronic platforms. Notable among such media are social networking sites where connections are electronically established, as well as other tools and services which support online presence awareness of the connected persons.

As adopters of Web technologies, employees in organizations may not be immune from the culture of online connectedness. However, existent literature seems to lack studies about implications of employee online connectedness. Researchers have rather largely focused on other connectedness contexts like social capital accrual (Riedl, Köbler, Goswami, \& Krcmar, 2013), online learning (LaBarbera, 2013; Slagter van Tryon \& Bishop, 2009; Woods \& Ebersole, 2003), social media marketing (Hoffman, Novak, \& Kang, 2017) and non-organization related personal or group communication (Ahn \& Shin, 2013; Allen, Ryan, Gray, McInerney, \& Waters, 2014; Cornejo, Tentori, \& Favela, 2013; Savci \& Aysan, 2017). This paper addresses this gap by drawing attention to employee-supervisor relationship vis-a-vis online connectedness.

Some studies show that employee usage habits of Web-based media positively impact their proclivity to such tools and the consequent perceived usefulness of such tools for organizational communication (Cummings, Massey, \& Ramesh, 2009; Onobhayedo, 2017). In this light, employees may desire to establish online connection with co-workers for the purpose of maintaining relationships just as they do with other related persons outside the organization. Of particular interest here is the possible relationship between such online 
connection or lack thereof and the perceived openness of supervisors (or immediate managers). Understanding that perceived openness has been associated with employee satisfaction in organizations (Burke \& Wilcox, 1969; Pelz, 1952), we suggest that knowledge about the influence of supervisor-employee online connection on perceived openness of supervisors will be useful to organizations for establishing effective superior-subordinate relationship strategies.

Prior to the emergence of online connectedness culture, Rogers (1987) developed a model for the measurement of perceived communication openness which consists of 13 factors that incorporate the message sending and receiving behaviours of supervisors and peers related to suggestions, criticism, complaints, personal opinions, new ideas and bad news (p. 58). None of these factors puts into consideration the feeling of being connected as may be facilitated by presence awareness in the online space. In this paper, we present a test of relationship between perceived openness of supervisors and online connection between supervisors and employees in two countries, namely Nigeria (an infrastructure-poor country) and Spain (an infrastructure-rich country).

\section{THE IMPORTANCE OF MANAGER OPENNESS}

Research has shown that the degree of openness in superior-subordinate communication affects the degree of satisfaction of employees not only with the immediate supervisor but also with the company as a whole, the job, and performance appraisal, among others (Burke \& Wilcox, 1969). Employees have also been said to favour managerial feedback that is characterized by acceptance and openness (Stull, 1986). Similarly, managers' communication openness was found by Kay and Christophel (1995) to be positively related to employee motivation. The results of their study confirm that a manager's openness is instrumental in predicting subordinates' willingness to perform organizational tasks and develop more conducive working relationships (p. 204). The importance of communication openness is also implicated in the suggestion by Nohria, Groysberg \& Lee (2008) that one of the ways to fulfill the drive to bond is to create a culture that promotes openness along with teamwork, collaboration and friendship. Overcoming barriers to open communication will therefore be beneficial to organizations.

From the perspective of organizational communication culture, openness to communication on the part of supervisors or managers has long been associated with the attainment of a positive communication climate in organizations (Dillard, 1986). According to Hill and Northouse (1978), management has traditionally assumed that positive communication climate leads to increased productivity, profitability and job satisfaction as well as reduced absenteeism, grievances and turnover. A positive communication climate tends to encourage and support commitment to the organization (Pace \& Faules, 1994).

The foregoing literature on the importance of perceived manager openness in organizations lends support to the relevance of academic studies that seek to further elucidate factors that influence such perception as the culture of online connectedness persists.

\section{HYPOTHESES FORMULATION}

As a primary hypothesis, we suggest that online connectedness between the supervisor and subordinate is likely to be positively related to the perceived openness of supervisors to communicate. In conceptualizing connectedness, Rettie (2003) put forward the notion that both communication and presence awareness are important factors in the creation of the feeling of being in touch or sense of connectedness. She further suggested that awareness systems may even be more important for connectedness than the content of the 
communication itself. In some other study, social awareness and social presence were also found to directly affect social connectedness (Riedl et al., 2013). In this study, the researcher therefore tests two manifestations of online connectedness namely online presence awareness and online "friend" connection as reflected in the two hypothesis $\mathrm{H} 1$ and $\mathrm{H} 2$ below:

H11: Presence display on social media is positively related to perception of openness of supervisors to communication.

H10: Presence display on social media has no relationship with the openness of supervisors to communication.

H21: Supervisor as "friend" on social network is positively related to perception of openness of supervisor to communication.

H20: Supervisor as "friend" on social network has no relationship with the perception of openness of supervisor to communication.

\section{METHOD}

The study was carried out by way of survey using questionnaire as instrument for data collection. Employees were asked to indicate whether their boss or supervisor is a "friend" or "contact" in any online social networks and whether they can normally tell when their boss is online. In addition, using a 7-point Likert scale, the employees were further asked to indicate how open they consider their boss to be with respect to communication with them.

The population of study included the combination of employed people in Spain and Nigeria. In order to facilitate access from different parts of both countries, questionnaire was published online using the survey service available at http://www.encuestafacil.com and the link was sent by email or through social network messaging to prospective respondents.

For reasons of subject diversity as well as reaching sufficient number of employed people in both countries, effort was made to reach the alumni members of the University of Navarra, Pamplona and Pan-Atlantic University, Lagos. This effort was complemented with a general appeal to friends and acquaintances to spread the message to as many people as possible that work in Spain or Nigeria. Linkedin, a social network service primarily focused on networking among professionals, was leveraged on to send individual requests to prospective respondents, in an attempt to maximize returns from employed people who are the target of the survey. About a thousand of such messages were sent through Linkedin.

Six hundred and eighty five (685) responses were received online from respondents, 413 in Spanish language and 272 in English language. After data cleansing, a total of 556 cases were available for analysis, 352 from Spain and 204 from Nigeria.

\section{RESULTS}

Of the 556 cases available for data analysis, 419 were from male respondents and 137 from female respondents. Though respondents cut across age ranges as shown in Table 1, most $(78.2 \%)$ were within the age ranges of 25 to $34(39.9 \%)$ and 35 to 44 (38.3\%). Next in the order of representation was the age range of 45 to $54(14.2 \%)$. The least represented age groups were those above 64 and those below 25 . 
Table 1. Age Range of Respondents

\begin{tabular}{|l|c|c|}
\hline Age Range & Number of Respondents & Percentage of Respondents \\
\hline Below 25 & 18 & 3.2 \\
\hline $25-34$ & 222 & 39.9 \\
\hline $35-44$ & 213 & 38.3 \\
\hline $45-54$ & 79 & 14.2 \\
\hline $55-64$ & 21 & 3.8 \\
\hline Above 64 & 3 & 0.5 \\
\hline Total & $\mathbf{5 5 6}$ & $\mathbf{1 0 0}$ \\
\hline
\end{tabular}

Besides gender and age, respondents were distributed across various industry sectors as shown in Table 2. Education was most represented (18.9\%) and closely followed by professional firms and services (17.8\%) as well as telecommunications/information and communication technology (16.5\%). A number of respondents also came from sectors like media and entertainment (10.4\%), financial services (6.8\%), manufacturing (6.7\%), health sector (4.3\%), power, energy and utilities (4.7\%) as well as government and public sector (3.2\%).

The variety of industry sectors went beyond the groups presented in the questionnaire. Others indicated by respondents include sectors like construction, non-governmental organizations (NGOs), research, culture, tourism and sports.

Table 2. Respondents' Industry Sectors

\begin{tabular}{|l|c|c|}
\hline \multicolumn{1}{|c|}{ Industry } & $\begin{array}{c}\text { Number of } \\
\text { Respondents }\end{array}$ & $\begin{array}{c}\text { Percentage of } \\
\text { Respondents }\end{array}$ \\
\hline Agriculture & 2 & 0.4 \\
\hline Education & 105 & 18.9 \\
\hline $\begin{array}{l}\text { Financial Services (including banking, insurance, and } \\
\text { investment) }\end{array}$ & 38 & 6.8 \\
\hline Government and Public Sector & 18 & 3.2 \\
\hline $\begin{array}{l}\text { Health (including public health, hospitals, ambulances, } \\
\text { and pharmaceuticals) }\end{array}$ & 24 & 4.3 \\
\hline Manufacturing & 37 & 6.7 \\
\hline Media and Entertainment & 58 & 10.4 \\
\hline $\begin{array}{l}\text { Telecom/Information and Communications } \\
\text { Technology (ICT) }\end{array}$ & 92 & 16.5 \\
\hline $\begin{array}{l}\text { Power, Energy and Utilities (e.g. electricity, oil and gas, } \\
\text { water supply, mining, etc) }\end{array}$ & 26 & 4.7 \\
\hline Professional Firms and Services & 99 & 17.8 \\
\hline Trading & 10 & 1.8 \\
\hline Transportation Systems & 5 & 0.9 \\
\hline Other & 42 & 7.6 \\
\hline Total & $\mathbf{5 5 6}$ & $\mathbf{1 0 0}$ \\
\hline
\end{tabular}

Similar to the sectors of work, the nature of work within the respective organizations were also quite varied as shown in Table 3. It may be worthwhile noting in this regard that even though the highest proportion of respondents were from the educational sector, teaching activity was not the most represented. General management/administration had the highest representation followed by client services. Teaching only came in the third place.

Other types of regular work were also indicated by some respondents, adding to the variety presented in the questionnaire. Among these were legal, editing, library, research and development, broadcasting as well as safety related tasks. 
Table 3. Respondents' Nature of Work

\begin{tabular}{|l|c|c|}
\hline \multicolumn{1}{|c|}{ Nature of Work } & $\begin{array}{c}\text { Number of } \\
\text { Respondents }\end{array}$ & $\begin{array}{c}\text { Percentage of } \\
\text { Respondents }\end{array}$ \\
\hline Accounting and Financial Control & 23 & 4.1 \\
\hline Client Services & 65 & 11.7 \\
\hline Customer relationship management & 25 & 4.5 \\
\hline General Management / Administration & 103 & 18.5 \\
\hline Human (Employee) resource management & 16 & 2.9 \\
\hline Internal Information Technology Services & 45 & 8.1 \\
\hline Facilities Maintenance Services & 10 & 1.8 \\
\hline Production & 34 & 6.1 \\
\hline Supply Chain Management / Purchasing & 10 & 1.8 \\
\hline Teaching & 51 & 9.2 \\
\hline Training & 15 & 2.7 \\
\hline Sales & 33 & 5.9 \\
\hline Other & 124 & 22.3 \\
\hline [Missing Data] & 2 & 0.4 \\
\hline Total & $\mathbf{5 5 6}$ & $\mathbf{1 0 0}$ \\
\hline
\end{tabular}

\section{Hypotheses Testing}

The perceived openness of boss reported were aggregated into three groups namely open, closed and neither open nor closed. The resulting variable with aggregated frequencies was tested for association with supervisor as "friend" or "contact" online and ability to normally tell when supervisor is online. The tests were done using Pearson chi-square test of association.

\section{H1 Test Result Summary:}

Pearson chi-square test of association shows that there is an association between presence display of supervisor and perceived openness of supervisor, $\chi 2(2, \mathrm{~N}=360)=11.940, \mathrm{p}<.01$.

\section{H2 Test Result Summary:}

Pearson chi-square test of association shows that there is an association between having supervisor as online "friend" or "contact" and perceived openness of supervisor, $\chi 2(2, N=361)$ $=15.832, \mathrm{p}<.001$.

\section{Survey Response Frequencies}

Survey Question 1: Is your boss (or supervisor) your "friend" or "contact" in any of your online social networks?

The response frequencies pertaining to survey question 1 is as shown in Table 4 . The respondents that declared that they have no boss (or supervisor) were treated as missing cases. This criterion was also applied to survey question two and three below, both having to do with perceived openness of supervisor.

Table 4. Is Boss a Friend or Contact Online?

\begin{tabular}{|l|c|c|c|c|}
\hline \multicolumn{1}{|c|}{ Value Label } & Frequency & Percent & $\begin{array}{c}\text { Valid } \\
\text { Percent }\end{array}$ & $\begin{array}{c}\text { Cum } \\
\text { Percent }\end{array}$ \\
\hline Yes & 167 & 30.04 & 46.26 & 46.26 \\
\hline No & 194 & 34.89 & 53.74 & 100.00 \\
\hline & 78 & 14.03 & Missing & \\
\hline Has no boss & 117 & 21.04 & Missing & \\
\hline Total & $\mathbf{5 5 6}$ & $\mathbf{1 0 0 . 0}$ & $\mathbf{1 0 0 . 0}$ & \\
\hline
\end{tabular}




\section{Survey Question 2: Can you normally tell when your boss is online?}

The response frequencies pertaining to survey question 2 is as shown in Table 5.

Table 5. Can Employee Tell When Boss is Online

\begin{tabular}{|l|c|c|c|c|}
\hline \multicolumn{1}{|c|}{ Value Label } & Frequency & Percent & $\begin{array}{c}\text { Valid } \\
\text { Percent }\end{array}$ & $\begin{array}{c}\text { Cum } \\
\text { Percent }\end{array}$ \\
\hline Yes & 164 & 29.50 & 45.56 & 45.56 \\
\hline No & 196 & 35.25 & 54.44 & 100.00 \\
\hline & 79 & 14.21 & Missing & \\
\hline Has no boss & 117 & 21.04 & Missing & \\
\hline Total & $\mathbf{5 5 6}$ & $\mathbf{1 0 0 . 0}$ & $\mathbf{1 0 0 . 0}$ & \\
\hline
\end{tabular}

Survey Question 3: How open do you consider your boss (or supervisor) to be with respect to communication with you?

Response frequencies for survey question 3 are as shown in Table 6.

Table 6. Perceived Openness of Boss to Communicate with Employee

\begin{tabular}{|l|c|c|c|c|}
\hline \multicolumn{1}{|c|}{ Value Label } & Frequency & Percent & $\begin{array}{c}\text { Valid } \\
\text { Percent }\end{array}$ & $\begin{array}{c}\text { Cum } \\
\text { Percent }\end{array}$ \\
\hline Very closed & 2 & .36 & .55 & .55 \\
\hline Closed & 6 & 1.08 & 1.65 & 2.20 \\
\hline A little closed & 11 & 1.98 & 3.03 & 5.23 \\
\hline Neither open nor closed & 24 & 4.32 & 6.61 & 11.85 \\
\hline A little open & 29 & 5.22 & 7.99 & 19.83 \\
\hline Open & 151 & 27.16 & 41.60 & 61.43 \\
\hline Very open & 140 & 25.18 & 38.57 & 100.00 \\
\hline & 76 & 13.67 & Missing & \\
\hline Has no boss & 117 & 21.04 & Missing & \\
\hline Total & $\mathbf{5 5 6}$ & $\mathbf{1 0 0 . 0}$ & $\mathbf{1 0 0 . 0}$ & \\
\hline
\end{tabular}

\section{DISCUSSION}

As a possible factor affecting positive communication climate or lack thereof, the perceived openness of supervisor or boss was posited to be related to employees' having their supervisors as contact or "friend" on social media site (H2) as well as presence display of such bosses to their subordinates (H1). Feedback from respondents show that there is a highly significant relationship $(\mathrm{p}<.01)$ between perceived openness of supervisor and the ability of the employee to tell when the supervisor is online thus rejecting the null hypothesis of $\mathrm{H} 1$.

The trends in the cross tabulated frequencies suggest that a supervisor is more likely to be considered open if subordinates can normally tell when he or she is online. For example, among those that considered their boss as closed, only $21.1 \%$ can tell when the boss is online. Whereas, almost half $(48.9 \%)$ of those that considered their boss as open can tell when their boss is online. Similarly, among those that can tell when the boss is online, $94.5 \%$ consider their boss as open. Lesser proportion (82.7\%) of those that cannot tell when their boss is online considered their boss as open. Perhaps even more pronounced is the finding that among those that seem to show reservation about declaring their boss as open (i.e. those that declared their boss as neither open nor closed), the majority (79.2\%) indicated that they cannot tell when their boss is online.

Significantly $(\mathrm{p}<.001)$, perceived openness of supervisor was found to be associated with having supervisor as online "friend" or contact suggesting that the null hypothesis of H12 may also be rejected. Trends similar to that of $\mathrm{H} 1$ was observed in $\mathrm{H} 2$. For example, only $26.3 \%$ of those that consider their boss as closed have their boss as online contact whereas $50 \%$ of those 
that consider their boss as open had their boss as contact online. Similarly, among those that had their boss as friend or contact online, 95.2\% consider their boss as open whereas among those that do not have their boss as friend online, lesser proportion (82\%) considered their boss as open. Like the case of $\mathrm{H} 1$, majority $(87.5 \%)$ of those that declared their boss as neither open nor closed do not have their boss as online contact. Similarity in trends can be observed across the two countries studied as well as across gender.

\section{CONCLUSION}

In this work, we set out to study whether online connectedness between supervisor and subordinate impacts the perceived communication openness of managers by their employees. Online connectedness was represented by the existence of connection in social network as well as habitual awareness of online presence of supervisor on the part of the employee. Results show that the two connectedness scenarios positively impact the perceived openness of managers. It could be inferred from these findings that openness exhibited by supervisors online could enhance the level of positive communication climate as the latter has been suggested to be influenced by the perceived openness of the immediate supervisor. This finding suggests that managers should be favourably disposed towards connecting online with their organizational subordinates.

We recommend further research that would extend the work of Rogers (1987) by including online connectedness as a possible co-factor in the measurement of perceived communication openness in organizations.

\section{References}

Ahn, D., \& Shin, D.-H. (2013). Is the social use of media for seeking connectedness or for avoiding social isolation? Mechanisms underlying media use and subjective well-being. Computers in Human Behavior, 29(6), 2453-2462.

Allen, K. A., Ryan, T., Gray, D. L., McInerney, D. M., \& Waters, L. (2014). Social Media Use and Social Connectedness in Adolescents: The Positives and the Potential Pitfalls. Australian Educational \& Developmental Psychologist, 31(1), 18-31.

Burke, R. J., \& Wilcox, D. S. (1969). Effects of Different Patterns and Degrees of Openness in Superior-Subordinate Communication on Subordinate Job Satisfaction. Academy of Management Journal, 12(3), 319-326. https://doi.org/10.2307/255179

Cornejo, R., Tentori, M., \& Favela, J. (2013). Enriching in-person encounters through social media: A study on family connectedness for the elderly. International Journal of Human-Computer Studies, 71(9), 889-899.

Cummings, J., Massey, A. P., \& Ramesh, V. (2009). Web 2.0 proclivity: understanding how personal use influences organizational adoption. In Proceedings of the 27th ACM international conference on Design of communication SIGDOC '09; (pp. 257-264). Bloomington, Indiana, USA. https://doi.org/10.1145/1621995.1622047

Dillard, J. (1986). Communication climate and its role in organizations / Kommunikationsathmosspäre und seine Rolle in Organisationen. Communications: The European Journal of Communication, (2), 83.

Hill, S. K., \& Northouse, P. G. (1978). A Research Design for Studying Communication Climate within a Organization. Journal of Business Communication, 15(2), 37-44.

Hoffman, D. L., Novak, T. P., \& Kang, H. (2017). Let's Get Closer: Feelings of Connectedness from Using Social Media, with Implications for Brand Outcomes. Journal of the Association for Consumer Research, 2(2), $216-228$.

Kay, B., \& Christophel, D. M. (1995). The Relationships Among Manager Communication Openness, Nonverbal Immediacy, and Subordinate Motivation. Communication Research Reports, 12(2), 200-205.

LaBarbera, R. (2013). The Relationship between Students' Perceived Sense of Connectedness to the Instructor and Satisfaction in Online Courses. Quarterly Review of Distance Education, 14(4), 209-220.

Nohria, N., Groysberg, B., \& Lee, L.-E. (2008). Employee motivation: a powerful new model. Harvard Business Review, 86(7-8), 78. 
Onobhayedo, P. A. (2017). Implementing Web Technologies as Organizational Communication Media: A Study of Employee Adoption Likelihood. Journal of Business Theory and Practice, 5(2), 120. https://doi.org/10.22158/jbtp.v5n2p120

Pace, R. W., \& Faules, D. F. (1994). Organizational communication (Vol. 3). Englewood Cliffs, N.J.: Prentice Hall.

Pelz, D. C. (1952). Influence: A Key to Effective Leadership in the First-Line Supervisor. Personnel, 29, $209-217$.

Rettie, R. (2003). Connectedness, awareness and social presence. In 6th Annual International Workshop on Presence. Aalborg, Denmark.

Riedl, C., Köbler, F., Goswami, S., \& Krcmar, H. (2013). Tweeting to Feel Connected: A Model for Social Connectedness in Online Social Networks. International Journal of Human-Computer Interaction, 29(10), 670-687.

Rogers, D. P. (1987). The Development of a Measure of Perceived Communication Openness. Journal of Business Communication, 24(4), 53-61.

Savci, M., \& Aysan, F. (2017). Technological Addictions and Social Connectedness: Predictor Effect of Internet Addiction, Social Media Addiction, Digital Game Addiction and Smartphone Addiction on Social Connectedness. Teknolojik Bağımlılıklar ve Sosyal Bağlılık: Internet Bağımlılığı, Sosyal Medya Bağımlılığı, Dijital Oyun Bağımlılığı ve Akıllı Telefon Bağımlılı̆̆ının Sosyal Bağlılığı Yordayıcı Etkisi., 30(3), 202-216.

Slagter van Tryon, P. J., \& Bishop, M. J. (2009). Theoretical foundations for enhancing social connectedness in online learning environments. Distance Education, 30(3), 291-315.

Stull, J. B. (1986). Demonstrating Empathy for Foreign-Born Employees through Openness and Acceptance: A Quasi-Experimental Field Study. Journal of Business Communication, 23(2), 31-40.

Woods, R., \& Ebersole, S. (2003). Using Non-Subject-Matter-Specific Discussion Boards to Build Connectedness in Online Learning. American Journal of Distance Education, 17(2), 99. 